\title{
A Definição do Voluntário na Ethica Eudemia II.9
}

Inara Zanuzzi (UFPR)

This article intends to discuss the relation between the three clauses which appear in the definition of the voluntary action in Ethica Eudemia II.9: i) it depends on the agent himself not to do the act, ii) he does it not in ignorance and iii) he does it because of himself. If the first clause could be satisfied irrespectively of the other two, there would be some difficulty to make this definition consistent with Aristotle's contention in chapter 6 of the same book of Ethica Eudemia, from which it can be inferred that every act which depends on the agent is caused by himself and every act which is caused by himself is voluntary. So that it is not possible for an act to depend on the agent and not be voluntary. To solve this difficulty, it is proposed, rather tentatively, that the act mentioned in the first clause is to be interpreted not in particular, but in general terms. So interpreted, the role of Aristotle's first clause would be to restrict the range of the application of the definition to certain kinds of movements, namely, to those kinds which we could have not done, thereby excluding men's natural activities.

O propósito deste artigo é analisar a seguinte definição do voluntário dada na Ethica Eudemia, II.9, 1225b8-10:

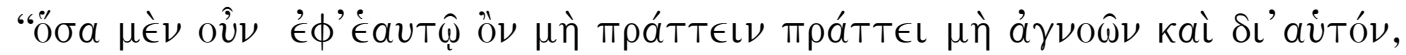

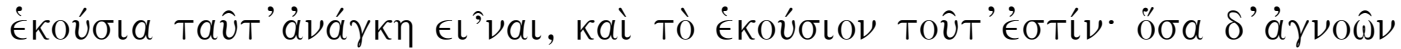

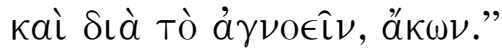

Esta passagem pode ser assim traduzida: “Aqueles atos, então, que [alguém] faz não ignorando e devido a ele próprio, dependendo dele mesmo não fazê-los, são necessariamente voluntários e o voluntário é isso. Aqueles que [ele faz] ignorando e devido ao ignorar, [faz] involuntariamente”. 
O problema que queremos discutir pode ser resumido na seguinte questão: as cláusulas ‘ele faz não ignorando e devido a ele próprio’ estipulam uma condição ulterior àquela estipulada na cláusula ‘dependendo dele mesmo não fazê-los’? Segundo M. Woods, isto é assim. Ele diz: “[...] as ações voluntárias são apenas uma subclasse daquelas dentro do poder do agente: uma condição ulterior é requerida” (Clarendon Press, 1992, p.119-120). Esta condição ulterior a que se refere Woods é $\delta \iota ’ a$ đóv, ‘devido a si próprio’, embora ele confesse que não seja fácil dizer o que pode significar esta condição ulterior.

T. Irwin, no artigo 'Reason and Responsibility in Aristotle', sustenta que ' $\delta \mathrm{\iota}$ ' aútó $\nu$ ' significa somente que ele age devido a seu próprio impulso ou desejo, enquanto 'dependendo dele não fazer' indica que o agente não deve estar submetido a uma compulsão irresistível que ultrapasse o que a natureza humana é capaz de suportar (University of California Press, 1980, p. $121)^{1}$.

Esta última interpretação parece adequada à discussão aristotélica que precede a definição em análise aqui, pois nesta discussão três situações que produzem involuntariedade foram discutidas. A primeira situação que gera involuntariedade é quando uma força externa opõe-se a um impulso natural interno. O objetivo de Aristóteles ao introduzir esta definição do involuntário era mostrar que nem o continente nem o incontinente agem involuntariamente ainda que ajam contrariamente a um impulso interno. Eles não agem involuntariamente porque os impulsos que se opõem são ambos internos e ambos naturais. Ora, para que a ação fosse forçada era necessário que fosse contrária a um impulso natural. Na medida em que razão e desejo (os impulsos que se opõem no caso do continente e do incontinente) são ambos naturais e ambos comandantes de ação, mesmo havendo oposição entre eles, esta oposição não gera o involuntário (1224a13-b15). A segunda situação que causa dificuldade não trata da oposição entre desejo e razão, mas da necessidade de fazer uma escolha para evitar um mal maior e da necessidade envolvida naquelas situações em que o agente é movido por um impulso que ultrapassa o que sua natureza humana é capaz de suportar (1225a2-33). Nestes casos, diz Aristóteles, a ação não depende do agente. A terceira situação discutida é a da involuntariedade causada pela ignorância de circunstâncias relevantes (1225a36b8).

\footnotetext{
${ }^{1}$ Uma interpretação similar parece-nos foi desenvolvida também em Muñoz, Liberdade e Causalidade, Discurso Editorial, 2002, pp. 65-86.
} 
Ora, podemos fazer coincidir as situações discutidas e as cláusulas presentes na definição do voluntário. Se uma ação provocada por um impulso externo contrário a um impulso natural interno é involuntária e o involuntário é contrário ao voluntário, então a ação provocada por um impulso natural interno é voluntária. Tal pode ser o sentido da condição expressa em ' $\delta$ ' avंTóv'. Em seguida, as ações feitas sob ameaça de maiores males ou sob a influência de uma paixão insuportável para a natureza humana seriam excluídas porque elas não satisfazem a cláusula ‘dependendo do próprio agente não fazer’. Por último, se agir ignorando é causa do involuntário e a ignorância é contrária ao conhecimento e o voluntário é contrário ao involuntário, então agir com conhecimento é causa do voluntário.

Se a discussão precedente parece tão bem reproduzida na definição, por que deveríamos nos sentir incomodados com ela? O problema com esta interpretação é que seria possível que uma ação satisfizesse as cláusulas “com conhecimento e devido a si próprio’, mas não satisfizesse a cláusula 'depende dele próprio não fazer'. Nessa medida, aquilo que depende dele próprio não fazer ainda deveria ter condições próprias de estabelecimento. Segundo Irwin (1980, p.121), dependeríamos de um esclarecimento acerca do que a natureza humana é capaz de suportar. Ora, se isso é assim, todavia, ou seja, se a cláusula 'depende dele próprio’ tem condições de aplicação próprias e independentes das outras duas, pareceria em princípio possível que esta cláusula estivesse satisfeita e as duas demais não estivessem. Neste caso, uma ação poderia ser involuntária e ainda depender de nós.

Isso parece opor-se ao que Aristóteles defendeu ao princípio de sua discussão sobre o ato voluntário. No Livro II, capítulo 6, da Ethica Eudemia, Aristóteles introduziu a questão do elogio e da censura e defendeu que somente podemos ser elogiados e censurados por aquilo de que somos nós próprios as causas. Ora, somente somos nós próprios as causas, por oposição à necessidade, ao acaso e à natureza, quando depende de nós fazer e não fazer. A seguir, Aristóteles pergunta de quais tipos de atos somos nós próprios as causas e responde que é opinião comum que são os atos voluntários e os escolhidos deliberadamente. Sendo assim, se os atos os quais depende de nós não fazer são os atos dos quais somos nós próprios as causas e se somos nós próprios causas dos atos voluntários, é evidente que os atos os quais depende de nós próprios não fazer são os atos voluntários. E, visto que todas estas implicações valem em ambos os sentidos (são, de fato, equivalências), segundo o início de sua discussão, são os mesmos atos os quais depende de nós fazer e não fazer e que são voluntários. Sabemos que os atos que dependem 
de nós são aqueles elogiáveis e censuráveis e queremos saber quais são os atos que dependem de nós. Como iremos investigá-los? Investigando os atos voluntários, pois são estes aqueles que dependem de nós. Se isso é assim, investigar em que condições os atos são voluntários é investigar em que condições algo depende de nós. Assim sendo não pareceria possível que um ato fosse involuntário e ainda dependesse de nós.

Nosso propósito é, então, considerar as possíveis leituras alternativas desta passagem e ver se é possível ou não resolver este problema. Uma primeira observação a fazer é que a cláusula ‘dependendo dele não agir’ é uma oração subordinada da oração principal que coordena as outras duas cláusulas. Visto que esta constitui-se numa oração subordinada, talvez possamos investigar que espécie de subordinação e, portanto, de dependência tem ela com as cláusulas da oração principal.

Vamos partir, então, da seguinte tradução da definição em questão:

i) São voluntários os atos que ele faz não ignorando e devido a si próprio, quando depende dele não fazê-los.

Numa certa leitura desta tradução, ela implicaria que:

i’) São involuntários os atos que ele faz não ignorando e devido a si próprio, quando não depende dele não fazê-los.

O que permitiria essa implicação é a suposição que seria possível negar somente a primeira cláusula, mantendo as demais inalteradas, e obter como resultado uma ação involuntária. Se isso é assim, a cláusula 'quando depende dele não fazer' é uma condição do ato voluntário. Uma tal implicação não é expressamente feita por Aristóteles. Com efeito, ele diz que: “Aqueles atos, então, que [alguém] faz não ignorando e devido a ele próprio, dependendo dele mesmo não fazê-los, são necessariamente voluntários e o voluntário é isso. Aqueles que [ele faz] ignorando e devido ao ignorar, [faz] involuntariamente”. Aqui, parece que a involuntariedade resulta da negação de uma das condições coordenadas. Nesse caso, cabe perguntar qual o papel da cláusula contida na oração e, em especial, se a definição aristotélica não implicaria, por exemplo, que:

i”) São involuntários os atos que alguém faz ignorando (mesmo que faça devido a si próprio), quando depende dele não fazê-los.

Ora, qual poderia ser o sentido disto? Podemos interpretar (i”) da seguinte forma: a cláusula ‘dependendo dele não agir’ marca o domínio das atividades humanas em que os atos voluntários ou involuntários podem ocorrer. Por exemplo, atividades naturais como o 
envelhecimento, o crescimento dos cabelos e unhas, a digestão, não são atividades que dependem da própria pessoa. Destas, então, não está em questão se ele as faz ignorando ou não, se são devido a ele próprio ou não. Somente daquelas que depende dele não fazê-las podemos perguntar se ele as fez por ignorância ou não, devido a si mesmo ou não. As ações daquele tipo tal que depende dele não fazer, se ele as faz por ignorância ou não devido a si próprio, ou seja, sem saber alguma circunstância relevante da ação ou devido a uma força externa, são involuntárias. A cláusula 'quando depende dele não fazer' não é compreendida aqui como condição do ato voluntário. Ela somente delimita o domínio em que a definição do voluntário (que consiste nas demais cláusulas) pode aplicar-se.

Nessa interpretação, como ficariam (a) as ações devido à ameaça de males maiores e (b) as ações devido a alguma afecção que ultrapassa o que a natureza humana é capaz de suportar? Essas ações também seriam consideradas da classe genérica daquelas que dependem dele não fazer. Elas não satisfariam a condição de serem devido ao próprio agente ( $\delta$ ' 'aن̛Tóv). Essa posição pode ser defendida se observarmos que Aristóteles salientou, com respeito às ações do

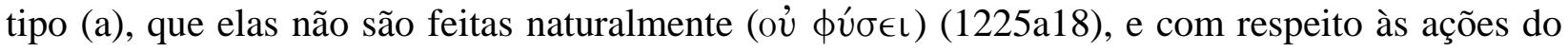
tipo (b), que somente o que não ultrapassa o que a natureza humana pode suportar pode ser referido à natureza humana (1225a25-26). Se a expressão ' $\delta$ ' 'avitóv' delimitava o que fosse gerado por um princípio interno e natural ao agente, as ações do tipo (a) e (b) não seriam ' $\delta \mathrm{\iota}$ ' aíTóv'.

Devemos, é verdade, admitir que a frase "São involuntários os atos que alguém faz ignorando, quando depende dele não fazê-los” sugere que são os mesmos atos que ele faz ignorando e que depende dele não fazer. Ora, isso seria, sem dúvida, impossível, pois não é possível sustentar que alguém ignora o que está fazendo e que depende dele não fazer isto mesmo que ignora estar fazendo. Sendo assim, o melhor seria compreender a oração que contém o partícipio não como uma oração temporal, mas como uma oração que estabelece uma restrição, da seguinte forma:

ii) Aqueles atos que ele faz não ignorando e devido a si próprio são voluntários, desde que dependa dele próprio não fazê-los.

Embora a conjunção 'desde que' tenha benefícios em relação a conjunção 'quando', na medida em que a segunda parece implicar que se esteja falando dos mesmos atos, enquanto a primeira não, para que esta afirmação tenha o sentido que propomos é preciso ainda assim 
compreender (e isso não fica claro a partir somente do texto aristotélico) que a restrição não é operada sobre os atos que são efetivamente feitos, mas sobre a classe dos atos que podem ser executados pelos homens, estando incluindo nesta classe os movimentos naturais, tais como o batimento cardíaco. Nesta classe de “atos”, são selecionados pela cláusula em questão aqueles os quais depende dos homens não fazer e sobre estes é possível perguntar se foram feitos 'sem ignorância e devido ao próprio homem’, ou seja, se foram voluntários, ou se estas condições não foram satisfeitas, caso em que foram involuntários.

Por oposição a esta interpretação, como podemos compreender (i’)? Uma primeira observação é que (i’) não seria dito expressamente por Aristóteles, mas poderia ser um corolário do que ele está dizendo, de acordo com a interpretação da cláusula 'dependendo dele não fazer'. Se consideramos que a cláusula ‘dependendo dele não fazer’ distingue dois tipos de situações particulares, não mais a classe das ações que podem ser feitas ou não pelo homem, então teríamos que, em algumas situações particulares em que é possível agir sem ignorância e devido a si próprio, é possível que ocorra que não dependa de nós não fazer a ação. Essas situações seriam aquelas descritas acima como ações de tipo (a) e (b).

Como observamos anteriormente, se as situações (a) e (b) são capturadas por condições distintas e independentes das demais cláusulas, então uma ação poderia não satisfazer as demais e ser involuntária, e poderia ainda assim depender do próprio agente. Para evitar esta conclusão, e ainda sustentar que a cláusula 'depende do próprio agente' fosse compreendida em termos particulares, deveríamos procurar estabelecer uma relação entre as cláusulas tal que uma ação não pudesse satisfazer as cláusulas coordenadas sem satisfazer a cláusula 'depende dele não fazer'. Se Aristóteles estivesse dizendo que:

(iii) São voluntários os atos feitos com conhecimento e devido a ele próprio, se depende dele próprio não fazer estes mesmos atos, isto é, na circunstância particular.

Poderíamos compreender esta frase como se a oração 'se depende dele não fazer estas mesmas ações’ fosse a condição suficiente da conjunção 'ele faz não ignorando e devido a si próprio’. Nesse caso, não ocorre que seja possível alguém agir com conhecimento e devido a si próprio sem que a ação dependa dele, pois ‘agir com conhecimento e devido a si próprio’ é condição necessária de que dependa dele. Não é, todavia, suficiente. Portanto, poderíamos encontrar ações que, satisfeitas estas condições, ainda assim não dependessem do próprio agente. Tais seriam as ações do tipo (a) e (b). 
O problema aqui é que se Aristóteles pretendia que as condições dos atos voluntários esclarecessem quais atos são os que dependem de nós, ao introduzir a cláusula 'que dependa dele próprio não fazer’ como condição do voluntário, isso já não é mais possível. Precisamos saber quais atos dependem de nós nas circunstâncias particulares para podermos saber quais atos são voluntários.

É de se observar que na interpretação anterior (aquela em que a cláusula 'dependendo dele não fazer’ fosse compreendida em termos genéricos, isto é, na leitura (ii)), ainda precisaríamos poder fazer um teste para saber se o movimento é do tipo tal que depende de nós ou não para sabermos se este é um caso em que a definição do voluntário pode aplicar-se. Todavia, nessa hipótese, o teste é ao menos mais simples, pois não é necessário fazer uma investigação sobre o que a natureza humana é capaz de suportar para saber se o ato depende de nós (embora uma tal

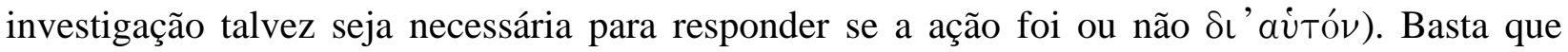
perguntemos em termos gerais se a ação, sob uma descrição genérica, é tal que está em poder do agente não fazê-la.

Haveria, por outro lado, razões para que Aristóteles tivesse defendido a definição do voluntário sob a interpretação que corresponde à leitura (ii)? Podemos dar como evidência disto a própria discussão inicial em que se pretende distinguir tipos de princípios e seus correspondentes tipos diversos de efeitos. O argumento, na verdade, não pretendia estabelecer, como se poderia erroneamente pensar, que os homens são princípios genéricos de ações que podem fazer de modo diverso, isto é, que os homens como classe podem gerar ações contrárias, mas como indivíduos podem gerar ações somente de um tipo. O argumento, ao contrário, pretendia defender que cada indivíduo pode gerar ações contrárias e que, nisso, os resultados de que ele fosse propriamente causa se diferenciavam dos resultados naturais, ou necessários, ou ocasionais. Ainda que, portanto, o argumento pretendesse atribuir aos homens individualmente tomados a capacidade para gerar efeitos contrários, o argumento também tinha por objetivo estabelecer que esta classe de efeitos, a saber, a daqueles que pudessem ter sido gerados contrariamente ao modo como foram, tendo no mesmo homem a causa, era a classe de efeitos que nos interessaria no momento em que nos interessamos pela atribuição de elogio e censura, pois somente deste tipo de efeito poderíamos ser corretamente elogiados e censurados. Estes efeitos são aqueles que têm no próprio homem sua causa e os atos dos quais o homem é causa são voluntários. Assim os efeitos 
que dependem do próprio homem são aqueles dos quais ele é causa e ele é causa dos atos voluntários.

Mesmo que alguém procurasse defender uma interpretação oposta a esta, ela não solucionaria o problema da passagem em questão, pois os mesmos problemas surgem quer interpretemos a cláusula 'dependendo dele não fazer' como se dissesse 'depende da natureza humana não fazer’ ou ‘depende dele próprio não fazer', onde 'dele próprio’ marcaria que é a mesma pessoa que pode fazer diferentemente. Isto é assim porque desde o princípio Aristóteles fez a equivalência entre essa cláusula, ser causa e ser voluntário. Assim, quer interpretemos que ‘depende dele não fazer' refira ao próprio sujeito ou à classe dos homens, permanece que esta cláusula não estaria bem colocada na definição do voluntário como condição dele.

Quando sugerimos que a cláusula 'depende dele não fazer’ refere-se à classe das ações que poderiam em princípio estar em poder de um agente, queremos dizer que a descrição genérica de certas ações - ou seja, independentemente das circunstâncias particulares - permite que as classifiquemos como uma que poderia estar ao alcance do agente não fazer (e aqui o 'agente' pode tanto significar o indivíduo quanto a classe dos indivíduos de mesmo gênero, de acordo como se interprete a posição de Aristóteles quanto a isso). No âmbito da distinção entre ações voluntárias e involuntárias não está em questão distinguir ações das quais o homem é causa daquelas que ele não pode ser causa de modo algum, como o envelhecimento. O envelhecimento não é uma ação involuntária. Uma ação involuntária tem de ser uma com respeito a qual poderíamos ficar em dúvida - no momento de atribuir censura ou elogio - se ela dependia do agente ou não. Assim sendo, a ação involuntária é tal que genericamente tomada ela poderia ter sido voluntária e o agente poderia ter feito de outro modo. Uma ação involuntária, em uma descrição genérica, como 'empurrar', sem a delimitação das suas circunstâncias e fins, pertenceria à classe das ações que dependem de nós não fazer. Este seria o objetivo de introduzir esta cláusula na definição do voluntário, ou seja, delimitar estas ações daquelas que não se encontram de modo algum no domínio daquelas que poderiam ter sido voluntárias ou involuntárias.

Se na Ethica Nicomachea esta cláusula não aparece, a razão disso pode ser que 'ter o princípio interno’ deve já distinguir a classe das ações que podem depender de nós daquelas que não podem de modo algum, assim como ' $\delta$ ' aưTó $\nu$ ' aqui deveria poder cumprir esta função. Se Aristóteles sentiu a necessidade de incluir esta distinção, isto talvez se deva ao modo como ele 
argumentou na Ethica Eudemia, isto é, partindo da distinção entre certos tipos de princípios e certos tipos de resultados a eles correspondentes. Em outra hipótese, a definição simplesmente sofre de problemas graves e Aristóteles fez bem em deixar de fora a cláusula 'dependendo dele não fazer’ na definição do voluntário na Ethica Nicomachea.

Bibliografia:

IRWIN, T. H., "Reason and responsibility in Aristotle”. In: RORTY, A.O. (Org), Essays on Aristotle's Ethics. Berkeley: University of California Press, 1980, pp.117-155.

MUÑOZ, A. A., Liberdade e Causalidade: Ação, Responsabilidade e Metafísica em Aristóteles. São Paulo: Discurso Editorial, 2002.

WOODS, Michael, Aristotle : Eudemian Ethics Books I, II, and VIII. 2nd ed. Oxford: Clarendon Press, 1992 (1996). 